\title{
ESTUDANTES, DOCENTES E PROFISSIONAIS NA ATENÇÃO BÁSICA: COEXISTÊNCIA SEGUNDO A FENOMENOLOGIA HEIDEGGERIANA
}

\author{
STUDENTS, PROFESSORS, AND PROFESSIONALS IN PRIMARY CARE: COEXISTENCE ACCORDING \\ TO THE HEIDEGGER PHENOMENOLOGY
}

\section{ESTUDIANTES, DOCENTES Y PROFESIONALES EN LA ATENCIÓN BÁSICA:COEXISTENCIA SEGÚN LA FENOMENOLOGÍA HEIDEGGERIANA}

\author{
Lucimar Aparecida Britto Codato ${ }^{1}$ \\ Mara Lúcia Garanhani ${ }^{2}$ \\ Alberto Durán González ${ }^{3}$ \\ Maria de Fátima Prado Fernandes ${ }^{4}$
}

Resumo O estudo buscou compreender a coexistência entre estudantes, docentes e profissionais em unidades básicas de saúde. Tratou-se de pesquisa de natureza qualitativa, com abordagem fenomenológica hermenêutica, apoiada no referencial teórico filosófico de Martin Heidegger, realizada com estudantes, profissionais da rede de serviços e docentes que acompanham estudantes em atividades realizadas em unidades básicas de saúde da região metropolitana de um município de grande porte do sul do Brasil. A coleta dos dados aconteceu entre os meses de novembro de 2013 e março de 2015, por meio de entrevistas gravadas e orientadas por um roteiro de questões. Os participantes foram selecionados intencionalmente, totalizando 23 entrevistados. A coexistência entre estudantes, docentes e profissionais na unidade básica de saúde mostrou-se permeada por diferentes modos de ser. Nela desvelaram-se conflitos ligados à linguagem, mais precisamente na verbalização e na escuta. Essa relação foi reconhecida como importante para o ensino-aprendizagem e para reflexões sobre adequações no processo de trabalho.

Palavras-chave educação superior; atenção primária à saúde; serviços de integração docente-assistencial; estágios; pesquisa qualitativa.
Abstract This study sought to understand the coexistence between students, professors, and professionals at basic health units. This was a qualitative research study with a hermeneutic phenomenological approach, based on the philosophical theoretical frameworks of Martin Heidegger and carried out with students, network services professionals, and professors monitoring students in their activities at basic health units in the metropolitan area of a large city in southern Brazil. Data were collected through recorded interviews guided by a list of questions from November 2013 to March 2015. Participants, totaling 23 respondents, were selected intentionally. Coexistence among students, professors, and professionals at the basic health unit proved to be permeated by different ways of being. They unveiled conflicts related to language, specifically in verbalization and listening. This relationship was recognized as important for teachinglearning and for reflections on adjustments in the work process.

Keywords higher education; primary health care; teaching-care integration services; internships; qualitative research. 


\section{Introdução}

A integração ensino-serviço de saúde é meio e fim para o cuidado de indivíduos e da população, uma estratégia indispensável para a qualificação do Sistema Único de Saúde (SUS) e, consequentemente, cumprimento de seus pressupostos. Essa aproximação é sinérgica para o alcance de avanços na integralidade da atenção no sistema público de saúde.

Transformações na formação e na atenção à saúde devem ser movimentos simultâneos e interligados (Feurwerker, 2002; Ceccim e Feuerwerker, 2004; Siqueira-Batista et al., 2013). Deve-se considerar que a interseção entre o ensino e o trabalho favorece a confluência de saberes, dos modos de ser e de ver o mundo, importantes para a formação em saúde e para a consolidação do modelo de atenção do SUS (Albuquerque et al., 2008), pois ameniza a dicotomia entre o ensino e a produção do cuidado (Pereira e Fracolli, 2009).

Assim, as atividades desenvolvidas pelos cursos de graduação em saúde em unidades básicas de saúde (UBSs) oportunizam ensino-aprendizagem num cenário atrelado à realidade das demandas de saúde da população. A compreensão das diversas conjunturas, das necessidades dos usuários e do contexto da existência de cada pessoa enriquece o processo formativo. É uma possibilidade para o rompimento de modelos tradicionais de ensino e para o desenvolvimento de competências que favoreçam a compreensão da dimensão essencial do cuidado, porque a formação torna-se mais significativa quando aliada à prática dos serviços (Albuquerque et al., 2008; Morita et al., 2010; Toassi et al., 2013; Fonseca et al., 2014; Sales, Marin e Silva-Filho, 2015).

No estudo aqui apresentado, a integração ensino-serviço de saúde na UBS, à luz do referencial heideggeriano, é compreendida como uma relação de coexistência entre profissionais, estudantes e a população. Diz respeito a 'ser-com-outro' em um espaço compartilhado na UBS. Nela, cada pessoa é indispensável à existência do outro, pois sem ele não existe o 'ser-com'. Critelli (1996, p. 65) ressalta que "nunca o eu pode cuidar da vida, tornando-a um acontecimento exclusivamente seu. Sua vida é um acontecimento que implica os outros. Os outros também acontecem juntos e através do eu".

Heidegger (2006) considera a natureza ontológica do humano, o ser que fala, pensa e simboliza. Para ele, ontologia diz respeito ao questionamento teórico e explícito do sentido do ser, e ôntico está ligado ao 'ente'. Designa 'ente' muitas coisas, em sentidos diversos. Inclui tudo que falamos, processos naturais, acontecimentos históricos, relações numéricas e espaciais. O próprio homem é um 'ente', no qual a questão do ser foi esquecida, porque em vez de questioná-lo, concebeu-se o ser do homem como evidência, no sentido de ser simplesmente dado, em conjunto com as demais coisas criadas. Para o pensador, 'ser-com' é um constitutivo essencial do 'ser-no-mundo'. Diz respeito à própria existência, na qual a pessoa humana, que o pensador 
denomina Dasein ou 'ser-aí' na tradução espanhola, pode relacionar-se por meio de diversas formas e possui a capacidade de questionar, indagar o sentido do seu ser e empreender uma busca sobre si; compreende-se a partir de sua existência e também das relações e comportamentos no mundo. $O$ 'ser-aí tem a tendência de compreender seu próprio ser a partir dos 'entes' com quem se relaciona e se comporta, de modo essencial, a partir do mundo.

De acordo com Heidegger (2006), o mundo no qual o ser humano existe é anterior ao mundo espacial, topográfico e interior; fundamenta-se no 'ser-em', que tem o sentido de habitar e morar. O autor concebe a ideia de que o 'ser-aí' está no mundo e se relaciona com ele segundo um modo de ser predominante. O 'ser-aí' é essencialmente 'ser-com', coabita e compartilha o mundo com os outros. Numa primeira aproximação e na maior parte das vezes, o 'ser-aí' se compreende a partir do que vem ao encontro no mundo circundante e também em decorrência do que se ocupa numa circunvisão. Logo, a coexistência entre estudantes, docentes e profissionais na UBS é uma possibilidade de 'ser-com-outro'.

Para Heidegger (2006), a compreensão é entendida como circular e reflexiva. Segundo Gadamer (1999), seus ensinamentos caracterizam-se pela constante interrogação e buscam revelar o próprio objeto de interrogação. Desse modo, focam o sentido do ser, seus modos e maneiras de expressão por meio do entendimento da experiência concreta vivida (Silva, Lopes e Diniz, 2008; Mc Connell, Chapman e Francis, 2009; Garanhani e Vale, 2010; Moreira, 2010; González et al., 2012). Assim, esse referencial mostrou-se pertinente para a compreensão das inquietações que moveram a realização do estudo aqui apresentado, configurando a questão de pesquisa: como se dá a coexistência entre estudantes, docentes e profissionais da área da saúde no espaço existencial das UBSs?

Este artigo é derivado de tese de doutorado (Codato, 2015) que buscou compreender os significados da integração ensino-serviço para a formação profissional em saúde, suas interfaces e os modos de 'ser-com-o-outro' - este último, foco deste manuscrito, no qual abordamos as relações identificadas entre estudantes, docentes e profissionais, quando estas pessoas coexistem em UBSs.

\section{Trajetória metodológica}

Tratou-se de pesquisa de natureza qualitativa com abordagem fenomenológica hermenêutica, apoiada prioritariamente na obra Ser e tempo, de Martin Heidegger $(1988,2006)$.

A pesquisa fenomenológica busca os significados, que são expressões claras sobre as percepções que a pessoa tem daquilo que está sendo investigado, e remete à totalidade das experiências vividas por um indivíduo. Nela, 
o pesquisador não está preocupado com os fatos e sim com o que os eventos significam para os pesquisados, mais precisamente no ângulo do sentido que esses fenômenos têm para aqueles que os vivenciam (Martins e Bicudo, 2005; Giorgi, 2007).

A hermenêutica é uma importante corrente do pensamento filosófico do século XX. Refere-se à arte da interpretação de forma ampliada. Inclui a compreensão de processos de experiências de vida em que a linguagem escrita, falada ou simbólica demonstra aspectos da realidade humana. Auxilia a revelação, a descoberta e o desvelamento de significados em textos ou linguagens e também das relações que são estabelecidas. Possibilita a compreensão do homem, de seu mundo e do próprio existir humano (Minayo, 2014; Araújo, Paz e Moreira, 2012). Para Minayo (2003), a hermenêutica é relevante para a compreensão como categoria metodológica no movimento e na atitude de investigação. Abre a possibilidade de interpretar, instituir relações, extrair conclusões em todas as direções, e esclarece as condições sobre as quais surge a fala.

A fenomenologia hermenêutica é importante abordagem de pesquisa, pois o conhecimento é dependente da compreensão subjetiva ou intersubjetiva dos fenômenos em suas diversas manifestações e contextos. A compreensão diz respeito ao sujeito que, por meio de suas pré-compreensões, estabelece um novo horizonte no presente, isto é, dá um novo sentido e uma nova forma de ser em si mesmo (Almeida, 2012).

De acordo com Heidegger (2006), a hermenêutica é o caminho que leva à compreensão, a qual opera no interior de um conjunto de relações, inseparável da existência do 'ser-aí'. Considera que, quando o 'ser-aí' compreende, ele projeta o seu ser para possibilidades abertas. O filosofar heideggeriano tem como característica a constante interrogação, busca revelar o próprio objeto de interrogação por meio da compreensão (Silva, Lopes e Diniz, 2008; Moreira, 2010; González et al., 2012).

Para Gadamer (1999), a interpretação inicia-se por meio de conceitos prévios que serão substituídos por outros mais adequados. Esse constante reprojetar perfaz o movimento de sentido do compreender, do interpretar, e constitui o processo descrito por Heidegger. Ele aponta que o círculo hermenêutico refere-se à lógica interna da compreensão hermenêutica, pois é necessário compreender o todo de um texto a partir das suas partes e estas a partir do todo. A compreensão é uma totalidade; e a linguagem, um meio de acesso.

Os dados da pesquisa aqui apresentada foram coletados entre outubro de 2013 e março de 2015, cuja amostra foi intencional com 23 entrevistados. Participaram um profissional de cada categoria que atuava em UBS: fisioterapeuta, farmacêutico, médico, cirurgião-dentista, enfermeira, agente comunitário de saúde, auxiliar de enfermagem e auxiliar de odontologia, e um docente de cada curso de graduação em saúde (enfermagem, fisioterapia, 
odontologia, medicina e farmácia) com maior tempo de atuação no acompanhamento de estudantes nas UBSs. Esses profissionais foram selecionados considerando que suas vivências seriam fundamentais para a compreensão do fenômeno pesquisado. Também integraram a pesquisa dois estudantes do último ano de graduação de cada um dos cinco cursos da área da saúde que realizavam estágios em UBSs. Tais entrevistas forneceram material suficiente para a compreensão do fenômeno. Partimos de quatro UBSs para realizar o estudo, indicadas pelos gestores do serviço e da instituição de ensino superior proponente, na fase exploratória da pesquisa, por serem as que recebiam a maior quantidade e diversidade de estudantes da instituição de ensino proponente.

As entrevistas foram realizadas pela pesquisadora principal e transcritas, de forma integral e literal, por três pessoas com experiência nessa atividade, com o objetivo de manter a maior fidelidade possível das expressões, termos e conteúdos paraverbais (entoações, ênfases, pausas) que foram manifestados pelos sujeitos de pesquisa. Após essa etapa, a referida pesquisadora simultaneamente ouviu todas as gravações e conferiu as transcrições das entrevistas. Segundo Merighi (2000), esse momento é uma oportunidade para o pesquisador familiarizar-se com as descrições e começar a identificação de aspectos relevantes relacionados à pesquisa.

Utilizaram-se os procedimentos preconizados por Josgrilberg (2000) para a realização da busca do sentido da integração ensino-serviço, entendido como fenômeno a ser desvelado. Inicialmente, cada transcrição, individualmente, foi lida e relida várias vezes. Num segundo momento, identificaram-se as unidades de sentido relacionadas à integração ensino-serviço de saúde de cada entrevista. Depois foram identificadas as unidades de sentido de cada grupo pesquisado (docentes, estudantes e profissionais). Em seguida, as unidades de sentido de todos os grupos foram relacionadas entre si, buscando-se os pontos de ligação para revelar os significados da integração ensino-serviço de saúde. Essas duas últimas etapas foram desenvolvidas por meio da elaboração de vários mapas conceituais. O salto para 'dentro' do círculo hermenêutico aconteceu por meio de reflexão, pela busca da singularidade e da pluralidade que oportunizaram a interpretação e a compreensão do fenômeno. Nessa etapa também foi utilizado o diário de campo que, em alguns momentos, contribuiu para ampliar a análise dos dados.

Para manter o anonimato, as entrevistas realizadas receberam codificação alfanumérica: P (profissional), E (estudante) e D (docente). Assim, D3 e E3 significam, respectivamente, o terceiro docente e o terceiro estudante entrevistados. As questões norteadoras para as entrevistas foram: 1) Quando eu falo integração ensino-serviço de saúde, o que vem a sua cabeça? 2) Como você experiencia a integração ensino-serviço de saúde aqui na UBS? 3) O que significa para você integração ensino e serviço de saúde? 
4) Qual a sua atuação/papel nesta integração? 5) Como é o processo de trabalho local compartilhado entre profissionais, estudantes e docentes? 6) Como você vê a UBS como espaço para a formação profissional em saúde? Cabe ressaltar que estas questões adaptaram-se à dinâmica e singularidade de cada entrevista. Houve aspectos que surgiram ou foram aprofundados com base em questionamentos derivados das respostas dos entrevistados.

A pesquisa foi aprovada pelo Comitê de Ética em Pesquisa da Universidade Estadual de Londrina, Paraná (parecer CEP/UEL 204/2013 - CAAE 21677913.4.0000.5231), e seguiu os pressupostos da resolução n. 466/12 do Conselho Nacional de Saúde.

\section{Resultados e discussão}

Os resultados foram apresentados e discutidos com base em aplicações do pensamento heideggeriano, o qual se mostrou adequado para a compreensão das relações que permeiam a coexistência de docentes, profissionais e estudantes em espaços existenciais da atenção básica. A análise dos dados, nessa perspectiva, possibilitou a identificação das seguintes relações na UBS: estudante-estudante, estudante-docente, estudante-profissional, profissional-docente, profissional-profissional e estudante-população. No estudo não foi encontrado resultado 'ser-com-outro' envolvendo docente-docente.

\section{'Ser-com' estudante-estudante}

Na maioria das vezes, essa convivência se dava entre estudantes do mesmo curso e raramente entre estudantes de diferentes cursos.

Os estudantes de outros cursos eu não encontro durante esse estágio na UBS (E-4).

Chamou a atenção o fato de estudantes oriundos de diferentes cursos habitarem simultaneamente o mesmo espaço extramuros da universidade, o qual poderia favorecer a aproximação entre essas pessoas. Também poderia oportunizar trabalho conjunto e articulado entre estudantes de diferentes graduações, visando à integralidade da atenção. Entretanto, a relação ali estabelecida parecia similar à que acontece dentro dos muros da universidade, pois havia limitação e, ao mesmo tempo, persistia o desafio de implementação ou fortalecimento de relações integradoras e interdisciplinares, as quais são possibilidades de 'ser-com-outro'.

O espaço existencial da UBS, ainda que compartilhado por diferentes estudantes, nem sempre favorece o estabelecimento ou fortalecimento de relações integradoras e interdisciplinares por ser, na maioria das vezes, carregado 
da impessoalidade constitutiva dos ambientes profissionais e educacionais. Essa sustentação se dá mediante um processo de conhecimento, interação e troca de informações. Assim, embora nesse contexto exista a possibilidade de se transitar entre a impessoalidade e a aproximação do mundo ôntico do ensino em saúde com o do serviço de saúde, ainda por vezes torna-se distante perceber e entender aquilo que é conhecido de imediato, pois a intenção do fortalecimento e de ter proximidade mais efetiva dessa realidade remete ao estudante identificar a necessidade de olhar para a temporalidade como 'condição ontológica', o que significa buscar o que ainda não se olhava.

Dessa forma, os estudantes pareciam ter ocupação similar à que acontece no mundo do ensino, ou seja, fragmentada. Esse resultado apontou a necessidade de as pessoas que compartilhavam esse espaço existencial reavaliarem como tem se dado essa ocupação, refletirem sobre a amplitude e as potencialidades dessa ocupação e, por conseguinte, sobre estratégias para alcançá-las ou otimizá-las. Como 'seres-no-mundo' as pessoas estão sempre de maneira compartilhada, e o estabelecimento das relações depende da compreensão, da abertura e dos modos de ocupação daqueles que coexistem na UBS.

No mundo das relações entre instituições de ensino e serviços de saúde, a possibilidade de integração é presente. Atitudes compartilhadas podem intervir no processo de integração ensino-serviço de saúde, algo ainda complexo para os estudantes, pois eles estão aprendendo a fundar-se na compreensão da integração, a qual nem sempre é clara na práxis. Nesse contexto, importante ressaltar o papel do docente que, atento a isso, pode se antecipar, auxiliando o estudante na compreensão das relações estabelecidas, fortalecendo as possibilidades de 'deixar o estudante intervir no mundo do aprender' para ver o que pode ser desvelado daquilo que se encontra encoberto sabendo, no entanto, que sempre permanecerão áreas ocultas para ambos desvelarem. Chamamos a atenção aqui para o fato de que um docente não envolvido nessa perspectiva pode se colocar tão cego quanto os estudantes, perdendo-se no seu papel de orientador.

\section{'Ser-com' estudante-docente}

Essa relação revelou-se permeada por duas situações diferentes. A primeira, quando o docente parecia não compreender ou reconhecer o espaço existencial compartilhado na UBS também como seu; parecia não ter clareza de que habitá-lo integrava o rol de suas atribuições, não necessariamente de forma rotineira, mas ele tinha um papel a cumprir nesse local.

Os professores do curso XX não vêm para unidade básica... mas tudo bem, acho que esse é um processo que vai mudar ainda. Para alguns outros cursos, isso já está claro, que a unidade básica é um campo de estágio importante (P-8). 
A fala do profissional P-8 - “Os professores do curso XX não vêm para unidade básica" - chamou a atenção primeiramente por poder ser interpretada como uma crítica velada à ausência da presença do docente em campo de estágio. Os estudantes podem ter sido lançados no mundo da UBS sem apresentarem ainda familiaridade com esse mundo, de modo que venha a se tornar inteligível para eles como ocupar espaço de possíveis ações que se constroem na cotidianidade do 'ser-no-mundo', com modos de ocupação que os permitam ir ao encontro do 'ente' de que se ocupam na cotidianidade em direção a compartilhar modos de ser e compreender com seus pares.

Podemos pensar que talvez alguns docentes não tivessem clareza, quer por desconhecimento, quer por não concordarem em decorrência de questões ideológicas, ou por resistências pessoais ou mesmo por comodismos, de que o exercício da docência muitas vezes requer a sua participação em diversificados cenários. Nessa situação e nesse espaço, o estudante convive exclusivamente com a população e com os profissionais, sem a presença do docente. Tal situação pode vir a ser um fator dificultador para a aproximação e o estabelecimento de vínculo entre estudante-população e estudante-profissional, porque a presença do docente poderia favorecer o estreitamento dessas relações.

Com base nessa reflexão, cabe indagar o que levou o profissional a dar esse depoimento e também em que espaço se encontra o cuidar na relação docente para com o aluno, no sentido de como o docente age consigo mesmo e com o estudante, já que este não está próximo de si, uma vez que é no cuidado que o 'ente' constrói e alcança a sua verdade. O docente deve estar presente no estágio junto ao estudante. Pode até ser parcialmente, pois são estudantes do último ano de graduação da sua jornada acadêmica. Sempre é desejável que haja um processo dialógico contínuo, com espaço para reflexão sobre questões que se mostram encobertas e podem vir a ser desveladas na compreensão do todo. Nesse contexto, a supervisão direta em campo pode aliar-se a diversificadas possibilidades disponibilizadas em redes sociais, as quais são instrumentos que, em sua manualidade, medeiam a comunicação e a construção do conhecimento entre docentes e estudantes.

Importante lembrar que a formação profissional em saúde requer processos de ensino-aprendizagem mais amplos e problematizadores, que incluem saberes com base em experiências vivenciadas em diversificados cenários de aprendizagem (Ceccim e Feuerwerker, 2004; Toassi et al., 2013; Fonseca et al., 2014). O que está em pauta não é a simples e pura aquisição de conhecimentos, mas o discernimento para mobilizá-los para a tomada de decisões ante as demandas apresentadas. Logo, o estreitamento da comunicação entre docentes e estudantes é indispensável.

A segunda situação apresentada acontece quando o docente compartilha esse espaço junto com o estudante. Neste caso, o docente tem a possibilidade de se preocupar ou não em 'ser-com' o estudante, condição esta 
que na sua ausência não pode ser experenciada. A UBS constituiu-se em um espaço a ser compartilhado, um espaço relacional entre pessoas em seus modos próprios ou não, ainda que possam estar juntas, por diversas vezes, influenciando o cotidiano assistencial e de formação profissional e sendo influenciadas por ele.

A gente discutia com os professores que faziam a supervisão do estágio de saúde coletiva e lá a gente discutia o caso e via o que poderia ser feito no próximo atendimento (E-3).

Estudantes e docentes, ao ocuparem espaço existencial compartilhado entre ensino e serviço de saúde, passam a coexistir entre si. A presença do docente é de vital importância para o estudante, principalmente quando o docente utiliza estratégias que facilitam o entendimento do que vem sendo aplicado na prática, de modo a viabilizar o alcance de uma possível compreensão em relação ao que está sendo trabalhado e integrado com a teoria. A fala também mostrou o quanto é significativo para o estudante ter ciência do planejamento prévio para os próximos atendimentos - o que poderia trazer à sua pessoa mais segurança e tranquilidade.

Esse espaço oportuniza o aprendizado do estudante em tempo real. Para Kahlmeyer-Mertens (2008), essa condição caracteriza uma forma de se importar com o estudante e de cumprimento da atribuição do 'ser-docente', e também constitui uma possibilidade de ensino-aprendizagem. Assim, reforçamos a ideia de que cabe ao docente tornar-se um companheiro no processo, oportunizando ao estudante um encontro consigo mesmo, para ele se educar, expor-se a si mesmo e descobrir possibilidades e significações em seu próprio caminho.

O existir é, consequentemente, estar presente como 'ser-no-mundo'. Estar próximo ao outro significa 'ser-com' aberto aos outros. Essa possibilidade inclui diferentes formas de habitar e compartilhar.

O mérito do docente está em fazer/deixar o estudante encontrar seu próprio caminho ao aprender. O estudante não aprende quando recebe apenas o que é oferecido; aprende quando experimenta, coloca em prática o que aprendeu. Esse resultado pode ser entendido como uma abertura do docente para realizar de modo presente o seu papel, além de suas atribuições dentro dos muros da universidade. Nessa situação, o docente deve buscar e até mesmo criar situações para que o estudante, de forma ativa, interaja com a equipe e com a população.

Cabe ao docente dar oportunidade para que o estudante se reconheça e atue como protagonista na construção de seu próprio caminho e aprendizado. Dessa forma, a educação torna-se um processo indireto, focada no estudante, com o docente como mediador. Para Leão (2002), o aprender é um tomar posse, ensinar é um dar e prestar. Ele considera que o que se dá e se presta 
não são conteúdos, técnicas, doutrinas, ou seja, apenas armazenamento de informações; destaca que deve se dar condições e indicações para se aprender por si mesmo o que já se tem.

Segundo Heidegger (2006), a existência é algo sempre aberto e com possibilidades de ser, na qual não cabe juízo de valor. Assim, quando o docente ocupa e compartilha o espaço existencial da UBS, ele se abre para outras possibilidades de 'ser-com-outro' e pode ressignificar a sua compreensão em relação à integração ensino-serviço de saúde.

Outra reflexão também pode ser feita em relação à percepção de como tal integração, nesse contexto, se fez presente. Reporta-nos à importância de se destacar que o papel docente na condição de 'ser-aí-com-outro' merece compreensão como um modo de existir, como alguém que também se encontra buscando novas maneiras de ser si mesmo - reflete-se que o ensinar somente faz sentido quando se dá de si ao estudante (compreensão pelo entendimento) e também no modo como se trabalha a realidade junto a ele e em qual perspectiva ela é olhada. Para isso, o docente deve estabelecer aproximação com o estudante, orientando e atendendo suas necessidades como aprendiz, ao mesmo tempo refletindo sobre como opera suas funções e processa a possibilidade de poder transformar a si, observando que tudo o que acontece no estágio está vinculado à interação que se estabelece na relação ensino-aprendizagem e na interpretação do mundo vivido.

Heidegger (1998) assinala que a impropriedade do 'ser-aí' é experimentada por meio da interpretação da decadência, a sua determinação mais forte. A impropriedade não significa algo como um não estar mais no mundo, visto que ela justamente perfaz um modo característico de 'ser-no-mundo', aquele que é totalmente absorvido pelo mundo e pela coexistência dos outros. Enfatiza que se a impropriedade é o modo de ser do 'ser-aí' que se manifesta na maior parte das vezes e o mais proximamente. Isso não significa que ela constitua o seu modo de ser mais originário e próprio, pois se a decadência é constitutiva do ser do 'ser-aí', a impropriedade que ela faculta não elimina sua possibilidade mais originária de ser, nem impede que suas relações para consigo, para com os outros e para com os 'entes' encontrados no mundo possam se dar a partir de si mesmo.

O impessoal tem a pretensão de nutrir e dirigir a vida e, dessa forma, remete ao 'ser-aí' uma tranquilização para a qual tudo está em perfeita ordem e todas as portas estão abertas. Esse modo de 'ser-no-mundo' é tentador, tranquilizante e também alienante. A decaída no impessoal não tem uma conotação negativa, de tal modo que precisasse ser eliminada, mas ela corresponde ao modo como de início e, na maioria das vezes, o ser humano é. A decaída desvela uma estrutura ontológica essencial do 'ser-aí', estrutura esta que, longe de determinar seu lado noturno, caracteriza na cotidianidade a totalidade de seus dias (Heidegger, 1998). 
Assim, docentes e estudantes coexistem vivenciando diferentes modos de estar no mundo na UBS, ora próprios, ora impróprios. Ao compreendermos que a relação educativa na perspectiva fenomenológica não é diretiva e sim espaço de oportunidades para estudantes e docentes, ela sempre deixará em aberto possibilidades de eles se reconhecerem como construtores de seu próprio caminho e aprendizado, resgatando suas relações consigo mesmos e com os outros.

\section{'Ser-com' estudante-profissional}

Essa relação se dá por meio da convivência com profissionais da mesma área da formação do estudante e também entre estudantes e profissionais de diversas áreas.

A gente fica ali com o nosso preceptor o tempo todo, então ele acaba te ajudando, te dando a instrução (E-8).

A fala apontou que a primeira situação acontece quando essa relação está focada na prestação da assistência inerente a cada núcleo profissional. Nela, o estudante tem a oportunidade de treinar a técnica, aprender com os profissionais em situações e condições diferentes das que se dão dentro dos muros da universidade.

A segunda situação possibilita que o estudante experiencie a atenção integral ao usuário e vivencie o trabalho dentro de uma equipe multiprofissional.

A gente pode discutir sobre um paciente, às vezes uma ACS tem uma informação, a enfermeira tem outra informação, vai juntando tudo, porque todo mundo conhece não só a pessoa, mas conhece a família, conhece o lugar onde vive, conhece a casa onde mora, as condições econômicas. A relação é com todos mesmo (E-10).

Nessa circunstância, o estudante não se limita à realização de ações assistenciais relativas à sua área de formação; o revelar-se e o fechar-se fundam-se nos modos de ser da convivência (Heidegger, 2006). A primeira situação, de maneira aplicada aos ensinamentos de Heidegger, é compreendida como um modo de convivência que pouco revela o todo do trabalho na UBS, porque se fecha mais em torno da assistência prestada por profissionais da mesma área de formação. A segunda situação é entendida como um modo de convivência que possibilita a revelação e a ampliação do olhar em relação ao todo da UBS, não se fecha em torno das atividades de núcleos específicas de cada categoria profissional. Podemos pensar que esta última situação tem maior possibilidade de ajudar o estudante a se posicionar e a vivenciar modos mais próprios de existir como 'ser-aí' e 'ser-com' a população. 


\section{'Ser-com' profissional-docente}

Tanto os docentes quanto os profissionais verbalizaram que essa relação é relevante para a reorganização e a reflexão sobre o processo realizado pelos profissionais do mundo do trabalho.

Quando os docentes estão passando por ali, já tiveram momentos assim que eu... sabe quando você para para repensar algumas posturas em algumas funções e ações (P-5).

Porém, reconheceram a presença de conflitos velados e desvelados no 'ser-com-o-outro' nesse espaço existencial.

Há conflitos tipo: da gente enxergar às vezes algumas necessidades que às vezes a equipe não tem o mesmo olhar. Eu penso que tudo é por olhares diferentes, até quanto aos papéis. Eu acho que, em alguns momentos, os olhares não estão na mesma direção... de algumas expectativas que eles tenham em relação ao nosso trabalho que, às vezes, não se concretizam, mas, da mesma forma que a gente... Então são situações que podem estar, se não forem bem esclarecidas, principalmente quanto às expectativas (D3).

Esses conflitos mostram-se ligados à linguagem, mais precisamente no falar, no ouvir e na não verbalização de anseios. Na linguagem, a pessoa tem a possibilidade de explicitar, velar ou revelar algum sentimento. Logo, escuta e silêncio são constitutivos da fala. Escutar é uma abertura da pessoa como 'ser-com-outro'. No silenciar, a pessoa está dizendo algo (Heidegger, 2006). Por um lado, os conflitos parecem acontecer pela insuficiência e/ou inadequação da linguagem; por outro, o fortalecimento da linguagem mostra-se necessário para o estreitamento das relações. Conflitos fazem parte do 'ser-no-mundo'; são oportunidades para aprimoramento das relações, desde que opiniões, sentimentos e expectativas sejam exteriorizados.

\section{'Ser-com' profissional-profissional}

Essa relação desvelou-se importante para a realização de adequações na rotina do processo de trabalho e para que o estudante possa desenvolver as atividades assistenciais.

O dia de aluno, por exemplo, aí a gente se organiza na questão de agenda, na questão de tempo (P-3).

Essas atitudes desvelam proximidade, acompanhamento e familiaridade com o ritmo e situações possíveis de serem desenvolvidas pelos estudantes. 
Podem ser compreendidas como formas de se importar com a população e com os estudantes no sentido de envolvê-los em práticas que a equipe considera viáveis para eles. No entanto, também podem ser entendidas como fatores limitadores à exposição do estudante a situações mais desafiadoras, que abririam oportunidades para reflexões, tomadas de decisões e aprendizados, com base em situações não corriqueiras, em contextos e possibilidades particularizados.

\section{'Ser-com' estudante-população}

Tanto os estudantes quanto os docentes reconheceram que a aproximação estudante-população é a mais intensa que acontece entre as pessoas que compartilham o espaço existencial na UBS.

O maior vínculo, e isso os estudantes verbalizam, que se forma é o vínculo paciente-família e estagiário (D-3).

Aqui [UBS] você cria um vínculo muito maior, tanto com os funcionários e até mais ainda com os usuários (E-10).

De forma aplicada aos ensinamentos de Heidegger (2006), o estabelecimento de vínculo pode ser compreendido como modo próprio de 'ser-com' o usuário, pois foi percebido como uma forma de se importar com a população, não como uma relação impessoal. Modos próprios e impróprios são possibilidades fundamentais da existência. A propriedade diz respeito a um poder ser a partir do seu próprio 'si-mesmo'. Na impropriedade, o impessoal diz respeito ao senso comum, às características públicas; revela-se como o sujeito mais real da cotidianidade, no qual a pessoa se mantém, na maior parte das vezes, imerso em regras e parâmetros. Assim, o vínculo com a população desvelou-se importante para o processo ensino-aprendizagem do estudante, inclusive de questões que envolvem ética, cidadania e comprometimento social, porque possibilita que o futuro profissional ouça, identifique demandas, busque soluções e coloque-se à disposição para servir.

\section{Considerações finais}

A ausência do 'ser-com-outro' envolvendo docente-docente no espaço existencial foi percebida como limitação para avanços em trabalhos interprofissionais e interdisciplinares. Tal relação poderia ser uma oportunidade para planejamentos, operacionalizações e avaliações conjuntas que serviriam para contribuir para a adoção de práticas mais integrativas. Essa convivência, nesse espaço 
existencial, também contribuiria para melhorias na formação integral do estudante, no processo de trabalho desenvolvido pela UBS, na educação permanente de profissionais e dos próprios docentes.

Deve-se ponderar que integrar ensino-serviço de saúde é complexo. Envolve 'ser-com-outro' e, nele, compreensões individuais e coletivas, que levam a escolhas, também ligadas aos modos de ocupação inerentes ao 'ser-no-mundo'. O estreitamento e o reavivamento constantes dessas relações são dependentes do fortalecimento da linguagem, que favorece a aproximação entre os dois mundos, principalmente por meio da escuta e da verbalização de sentimentos, expectativas e intencionalidades. O silêncio diz muito, mas, nesse caso, entendemos que ele precisa ser retomado e compreendido para que auxilie o estabelecimento de relações mais próprias em tal espaço existencial. Faz-se necessário agregar pessoas em torno de um diálogo franco, para que juntas possam refletir sobre por que integrar, como integrar, o que se espera dessa integração; entender como tem se dado a integração, quais os sentimentos que vêm permeando essa prática. É fundamental que as compreensões sejam circulares e se retroalimentem.

A coexistência entre estudantes, docentes e profissionais na UBS mostrou-se relevante para o ensino-aprendizagem e para reflexões sobre o processo de trabalho. Em alguns momentos, houve apenas justaposição de pessoas do mundo do ensino com as do trabalho, dentro do mesmo espaço; em outros, ocorreram experiências compartilhadas entre profissionais e estudantes de diferentes áreas.

Cada pessoa que compartilha esse espaço tem a possibilidade sempre aberta de fazer escolhas, mediante sua compreensão, disposição e linguagem, inerentes ao 'ser-no-mundo'. Essas escolhas podem ou não integrar pessoas dos dois mundos. Para tal aproximação, emerge o constante desafio de diálogos construtivos e reflexivos entre as pessoas envolvidas - espaço esse a ser construído integrando o pensar, o sentir e o agir, permeados pela abertura de 'ser-com-outro' no espaço compartilhado na UBS. Há necessidade de compreensão das relações existenciais, em seus modos próprios e impróprios e nos sentidos de ser para cada pessoa envolvida nessas relações. Importante lembrar que o entrelaçamento entre pessoas do mundo do ensino e o do trabalho, no espaço existencial da UBS, constitui-se sempre como possibilidade aberta para a qualificação do cuidado em saúde da população, desafio contínuo e permanente para o alcance da integralidade da atenção e da formação de profissionais da saúde voltados para esse objetivo.

O estudo aqui apresentado não buscou compreender o fenômeno pesquisado pelo olhar da população, o quarto elemento envolvido na integração ensino-serviço de saúde que acontece no espaço existencial. Foi uma escolha metodológica, constituindo uma limitação da pesquisa para a compreensão do 'ser-com' envolvendo docentes-estudantes-profissionais-população. Ao se 
considerar que nenhum fenômeno se mostra por inteiro, fica aberto esse desafio para estudos futuros que possam explorar tal perspectiva do fenômeno.

\section{Colaboradores}

Lucimar Aparecida Britto Codato conduziu a pesquisa de campo e atuou em todas as etapas da redação do artigo, com base em tese de doutorado; Mara Lúcia Garanhani e Alberto Durán González orientaram a tese de doutorado e auxiliaram na redação e na revisão do artigo; Maria de Fátima Prado Fernandes atuou na redação e na revisão crítica do artigo.

Resumen El estudio buscó comprender la coexistencia entre estudiantes, docentes y profesionales en unidades básicas de salud. Se trató de una investigación de naturaleza cualitativa, con enfoque fenomenológico hermenéutico, apoyada en la referencia teórica filosófica de Martin Heidegger, realizada con estudiantes, profesionales de la red de servicios y docentes que acompañan estudiantes en actividades realizadas en unidades básicas de salud de la región metropolitana de un municipio de gran porte del sur de Brasil. La recolección de datos tuvo lugar entre los meses de noviembre de 2013 y marzo de 2015, mediante entrevistas grabadas y orientadas por un conjunto de preguntas. Los participantes se seleccionaron intencionalmente, totalizando 23 entrevistados. La coexistencia entre estudiantes, docentes y profesionales en la unidad básica de salud se mostró permeada por diferentes modos de ser. En ésta se develaron conflictos vinculados al lenguaje, más precisamente en la verbalización y en la escucha. Esta relación se reconoció como importante para la enseñanza-aprendizaje y para reflexiones sobre adecuaciones en el proceso de trabajo.

Palabras clave educación superior; atención primaria de la salud; servicios de integración docente-asistencial; pasantías; investigación cualitativa. 


\title{
Notas
}

\author{
1 Universidade Estadual de Londrina, Departamento de Medicina Oral e Odontologia \\ Infantil, Londrina, Paraná, Brasil. \\ <lucimarcodato@gmail.com> \\ Correspondência: Rua Fernando de Noronha, 608, CEP 86020-300, Londrina, Paraná, \\ Brasil. \\ 2 Universidade Estadual de Londrina, Londrina, Paraná, Brasil. \\ $<$ maragara@hotmail.com> \\ 3 Universidade Estadual de Londrina, Departamento de Saúde Coletiva, Londrina \\ Paraná, Brasil. \\ $<$ betoduran80@gmail.com> \\ 4 Universidade de São Paulo, Escola de Enfermagem, Departamento de Enfermagem \\ em Orientação Profissional, São Paulo, São Paulo. \\ $<$ fatima@usp.br>
}

\section{Referências}

ALBUQUERQUE, Verônica S. et al. A integração ensino-serviço no contexto dos processos de mudança na formação superior dos profissionais da saúde. Revista Brasileira de Educação Médica, Rio de Janeiro, v. 32, n. 3, p. 356-362, 2008.

ALMEIDA, Rogério T. A hermenêutica ontológica heideggeriana. Legis Augustus, Rio de Janeiro, v. 3, n. 1, p. 72-82, 2012.

ARAÚJO, Janieiry L.; PAZ, Elizabete P. A.; MOREIRA, Thereza M. M. Hermenêutica e saúde: reflexões sobre o pensamento de Hans-Georg Gadamer. Revista da Escola de Enfermagem da USP, São Paulo, v. 46, n. 1, p. 200-207, 2012.

BRASIL. Ministério da Saúde. Conselho Nacional de Saúde. Resolução n. 466/12, de 12 de dezembro de 2012. Aprova as diretrizes e normas regulamentadoras de pesquisas envolvendo seres humanos. Brasília: Ministério da Saúde, 2012. Disponível em: <http://conselho.saude.gov.br/resolucoes/ 2012/Reso466.pdf>. Acesso em: 16 ago. 2013.
CECCIM, Ricardo B.; FEUERWERKER, Laura C. M. O quadrilátero da formação para a área da saúde: ensino, gestão, atenção e controle social. Physis: Revista de Saúde Coletiva, Rio de Janeiro, v. 14, n. 1, p. 41-65, 2004.

CODATO, Lucimar A. B. Integração ensino-serviço de saúde: uma compreensão por meio da fenomenologia heideggeriana. $142 \mathrm{f}$. Tese (Doutorado em Saúde Coletiva) - Programa de Pós-Graduação em Saúde Coletiva, Universidade Estadual de Londrina, Londrina, 2015.

CRITELLI, Dulce M. Analítica do sentido: uma aproximação e interpretação do real de orientação fenomenológica. São Paulo: Educ, Brasiliense, 1996.

FEUERWERKER, Laura C. M. Além do discurso de mudança na educação médica: processos e resultados. São Paulo: Hucitec, 2002.

FONSECA, Graciela S. et al. Educação pelo trabalho: reorientando a formação de profissionais da saúde. Interface: Comunicação, 
Saúde e Educação, Botucatu, v. 18, n. 50, p. 571-583, 2014.

GADAMER, Hans-Georg. Verdade e método. 3. ed. Petrópolis: Vozes, 1999.

GARANHANI, Mara L.; VALLE, Elisabeth R. M. Educação em enfermagem: análise existencial em um currículo integrado sob o olhar de Heidegger. Londrina: Eduel, 2010.

GIORGI, Amedeo. Concerning the phenomenological methods of Husserl and Heidegger and their application in Psychology. Collection du Cirp, Quebec, v. 1, p. 63-78, 2007.

GONZÁLEZ, Alberto D. et al. A fenomenologia heideggeriana como referencial para estudos sobre formação em saúde. Interface: Comunicação, Saúde e Educação, Botucatu, v. 16, n. 42, p. 809-817, 2012.

HEIDEGGER, Martin. Ser y tiempo. Santiago: Ed. Universitaria S.A., 1998.

HEIDEGGER, Martin. Ser e tempo. Tradução revisada e apresentação de Márcia Sá Cavalcante Schuback. Petrópolis: Vozes; Bragança Paulista: Editora Universitária São Francisco, 2006.

JOSGRILBERG, Rui S. O método fenomenológico e as ciências sociais. In: CASTRO, Dagmar S. P. (org.). Fenomenologia do existir. São Paulo: Universidade Metodista de São Paulo, 2000. p. 75-93.

KAHLMEYER-MERTENS, Roberto S. Heidegger e educação. Belo Horizonte: Autêntica, 2008.

LEÃO, Emmanuel. C. Aprendendo a pensar. 5. ed. Petrópolis: Vozes, 2002.

MC CONNELL-HENRY, Tracy; CHAPMAN, Ysanne; FRANCIS, Karen. Husserl and Heidegger: exploring the disparity. International Journal of Nursing Practice, Carlton, v. 15, n. 1, p. 7-15, 2009.

MARTINS, Joel; BICUDO, Maria A. V. A pesquisa qualitativa em psicologia: fundamentos e recursos básicos. 5. ed. São Paulo: Centauro, 2005.

MERIGHI, Miriam A. B. Enfermeiras obstétricas egressas da Escola de Enfermagem da Universidade de São Paulo: caracterização e trajetória profissional. $177 \mathrm{f}$. Tese (Livre Docência) - Escola de Enfermagem, Universidade de São Paulo, São Paulo, 2000.

MINAYO, Maria C. S. Hermêutica-dialética como caminho do pensamento social. In: MINAYO, Maria C. S.; DESLANDES, Suely F. (orgs.). Caminhos do pensamento: epistemologia e método. Rio de Janeiro: Editora Fiocruz, 2003, p. 83-107.

MINAYO, Maria C. S. O desafio do conhecimento: pesquisa qualitativa em saúde. 14. ed. São Paulo: Hucitec, 2014.

MOREIRA, Virginia. Possíveis contribuições de Husserl e Heidegger para a clínica fenomenológica. Psicologia em Estudo, Maringá, v. 15, n. 4, p. 723-731, 2010.

MORITA, Maria C. et al. Visita domiciliar: oportunidade de aprendizagem na graduação em odontologia. Revista de Odontologia da Unesp, Araraquara, v. 39, n. 2, p. 75-79, 2010.

PEREIRA, Juliana G.; FRACOLLI, Lislaine A. A contribuição da articulação ensino-serviço para a construção da vigilância da saúde: a perspectiva dos docentes. Revista Latino-Americana de Enfermagem, Ribeirão Preto, v. 17, n. 2, p. 167-173, 2009.

SALES, Patrícia R. S.; MARIN, Maria J. S.; SILVA-FILHO, Carlos R. Integração academia-serviço na formação de enfermeiros em um hospital de ensino. Trabalho, Educação e Saúde, Rio de Janeiro, v. 13 n. 3, p. 675-693, 2015.

SILVA, Jovânia M. O.; LOPES, Regina L.; DINIZ, Normélia M. F. Fenomenologia. Revista Brasileira de Enfermagem, Brasília, v. 61, n. 2, p. 254-257, 2008.

SIQUEIRA-BATISTA, Rodrigo et al. Educação e competências para o SUS: é possível 
pensar alternativas à(s) lógica(s) do capitalismo tardio? Ciência \& Saúde Coletiva, Rio de Janeiro, v. 18, n. 1, p. 159-170, 2013.

TOASSI, Ramona F. C. et al. Teaching at primary healthcare services within the Brazilian National Health System (SUS) in Brazilian healthcare professionals' training. Interface: Comunicação, Saúde e Educação, Botucatu, v. 17, n. 45, p. 385-392, 2013.

Recebido em 19/11/2015

Aprovado em 02/09/2016 